Article

\title{
Doing Civil Society-Driven Social Accountability in a Disaster Context: Evidence from Post-Earthquake Nepal
}

\author{
Nimesh Dhungana ${ }^{1,2}$ \\ ${ }^{1}$ Department of Methodology, London School of Economics and Political Science, London, WC2A 2AE, UK; \\ E-Mail: n.dhungana@lse.ac.uk \\ ${ }^{2}$ Department of International Development, London School of Economics and Political Science, London, WC2A 2AE, UK
}

Submitted: 15 April 2020 | Accepted: 21 July 2020 | Published: 10 December 2020

\begin{abstract}
While accountability has gained significant traction within the contemporary discourse on disaster governance, what it means and takes to be 'doing accountability' in promoting democratic governance of disasters remain scantly understood. Using the concept of social accountability and drawing on an ethnographic case study of a civil society-led accountability campaign in post-earthquake Nepal (the Mobile Citizen Help Desk, or MCHD), this article shows how MCHD sought to amplify local voices regarding failures in aid delivery and expanded opportunities for dialogue between disaster-affected communities and local powerholders. It highlights the potential of such initiative in safeguarding and promoting the rights of disaster-affected communities, while also helping overcome the post-disaster environment of mistrust, unfounded allegations and power inequalities. The article also draws attention to the challenges facing such an initiative. It shows that the effectiveness of such efforts in translating citizens' voices into state response was undermined by: (i) its incorporation into a donor-driven humanitarian accountability initiative, in which generating and reporting feedback to donors proved more pressing than amplifying citizen voice; and (ii) unclear structures of governance at the local level of service delivery, which impeded the civil society actors' aim to engage with 'the right authority.' The article draws attention to the political potential of social accountability in a post-disaster context, while also raising caution that such activism is unlikely to succeed in holding powerholders to account in the absence of supportive national bureaucratic and international aid structures.
\end{abstract}

\section{Keywords}

accountability; civil society; disaster; earthquake; ethnography; governance; Nepal; voice

Issue

This article is part of the issue "The Politics of Disaster Governance" edited by Dorothea Hilhorst (Erasmus University Rotterdam, The Netherlands), Kees Boersma (Vrije Universiteit Amsterdam, The Netherlands) and Emmanuel Raju (University of Copenhagen, Denmark).

(C) 2020 by the author; licensee Cogitatio (Lisbon, Portugal). This article is licensed under a Creative Commons Attribution 4.0 International License (CC BY).

\section{Introduction}

The Nepal earthquakes of April 25 and May 12, 2015 proved to be a major humanitarian crisis that claimed over 8,790 lives, injured over 22,300 and left more than 2,8 million people homeless (Government of Nepal, 2015). The emergency response to the earthquake was also characterised by public concerns over mismanagement, exclusion and corruption in humanitarian aid distribution (Regmi, 2016), while the government made explicit its plan to make the earthquake response partic- ipatory and accountable to the disaster-affected citizens (Government of Nepal, 2015).

That disasters are not just sites of human suffering but also spark citizen- or civil society-driven initiatives to challenge the top-down, state-driven model of recovery and reconstruction is increasingly recognised (Jalali, 2002; Schuller \& Morales, 2012). Disaster-affected citizens have been found to exploit disaster as a window of opportunity, demanding improved services and accountability from the government, and using information and communication technologies (ICTs) to expand 
the scope of inclusive and democratic response to the humanitarian disasters (Curato, 2018; Hayward, 2014; Meier, 2015; Mulder, Ferguson, Groenewegen, Boersma, \& Wolbers, 2016). Such societal invigoration was characteristic to the 2015 Nepal earthquake. Beyond the immediate environment of political contestation, several local and international civil society organisations launched initiatives, with an explicit or implicit aim of making the governance of the disaster inclusive and accountable (McMurren, Bista, Young, \& Verhulst, 2017). One such initiative called Mobile Citizen Help Desk (MCHD) was launched by two Nepal-based civil society organisations, with the mission of what the organisers termed "peoplepowered accountability" in Nepal's earthquake response and recovery.

This article presents an ethnographically oriented case study of the MCHD. In so doing, it seeks to contribute to the hitherto underexamined topic of the practice, potential and politics of civil society-based social accountability in promoting democratic and inclusive governance of disaster. The article first discusses key theoretical and practical underpinnings, together with recent critiques of social accountability, in the interest of framing the overall aim of this study. The article then explores the possibilities and limitations of the MCHD as a form of social accountability in the post-disaster context. The discussion section seeks to contribute to the ongoing debates surrounding democratic governance of post-disaster response and reconstruction.

\subsection{Social Accountability: Aims, Actors and Approaches}

Spurred by the long-standing concerns over the chronic performance deficit facing the public and development sector, social accountability has emerged as a form of citizen and civil society-driven activism to monitor the performance of powerholders and to hold them accountable for the delivery, quality and relevance of everyday public services (Gaventa \& McGee, 2013; Goetz \& Jenkins, 2005; Papp, Gogoi, \& Campbell, 2013). According to Goetz and Jenkins (2005), demanding accountability from powerholders is "inseparable from the language of rights" and consists of efforts "to obtain information, and to insist that officials engage in public reason-giving and thus, by definition, imposes obligations on holders of power" (p. 182). Making powerholders responsive to the everyday grievances of the citizens regarding the quality and delivery of public services, inefficiency and corruption, absenteeism and delays, constitutes the core focus of social accountability.

Recent scholarship has tried to document various forms of social accountability activism. Such activism has been found to range from ordinary citizens resorting to protests, to the naming and shaming of public officials to expose them for their wrongdoings (Peruzzotti \& Smulovitz, 2002). Others have documented how local communities in resource-constrained environments take an assertive approach to tackling chronic neglect and indifference from frontline officials (Hossain, 2010). In contrast to the more confrontational approaches, social accountability also involves citizens and public officials developing collaborative strategies to monitor the delivery of public goods and leverage local information to tackle public-sector underperformance (Björkman \& Svensson, 2009; Caseley, 2006). Such efforts often involve active engagement of local civil society actors to improve decision-making concerning the design and delivery of local services in a context marred by corruption and a governance deficit (Webb, 2012). Other forms of social accountability attempt to evoke moral responsibility among local authorities to respond to local demands, mainly when the formal systems of accountability are non-existent or weak (Tsai, 2007), and encourage mutual recognition of the rights of citizens and responsibilities of the state (Bukenya, 2016).

\subsection{Politics of Social Accountability}

Notwithstanding the potential and developments mentioned earlier, recent studies have called attention to the local and international conditions that tend to undermine the potential of social accountability in bringing public sector reforms (Gaventa \& McGee, 2013; Joshi, 2014).

Scholars acknowledge that citizen-driven accountability activism that promotes information and transparency in government operations (e.g., open government, audit reports, legislative hearings, complaint offices) do not necessarily follow through to improved conduct of powerholders. According to Fox (2007), transparency-based approaches, at best, are limited to producing accountability in the form of institutional answerability, but not sanctions in the event of underperformance or abuse of power. With civil society or local NGO actors often spearheading social accountability initiatives, the influence of international aid structures over the agenda and agency of local NGO actors also deserves attention. Scholars have argued that the unequal nature of partnerships within the aid sector often compels aidrecipient southern NGOs to privilege upward accountability to northern donors, at the cost of both learnings from interventions and downward accountability to communities they claim to serve (Ebrahim, 2005; Makuwira, 2006). Pressures to conform to a rigid reporting, monitoring and evaluation of aid interventions along specific indicators and measures have further reproduced power inequalities between northern and southern aid actors (Biradavolu, Blankenship, George, \& Dhungana, 2015; O'Connor, Brisson-Boivin, \& Ilcan, 2014), eroding local actors' ability to pursue "locally-intelligent means of programme improvement" (Shukla, Teedon, \& Cornish, 2016, p. 14).

The potential of social accountability activism also needs to be understood within the long-standing push by the international aid actors to deploy different standards and technologies of humanitarian accountabili- 
ty (CHS Alliance, Group URD, \& The Sphere Project, 2014; Sandvik, Jumbert, Karlsrud, \& Kaufmann, 2014; The Sphere Project, 2011). Critics, however, argue that accountability within international humanitarian governance is excessively driven by the interests of aid actors and their experts, at the expense of locally-driven accountability approaches (Barnett, 2013). A growing scholarly concern is that the ongoing global push to promote accountability and participation in disaster preparedness and response is hardly matched by its community-level operationalisation (Raju \& da Costa, 2018). Under donor-induced technologies of humanitarian accountability, the voice of local communities is misrepresented as mere feedback to bring short-term reforms in aid projects (Madianou, Ong, Longboan, \& Cornelio, 2016), masking the longer-term and political nature of accountability demands emanating from crisisaffected communities.

A related concern is also over the growing deployment of ICTs such as web portals, crowdsourcing techniques, mobile-based reporting and feedback and social media platforms to improve the public sector and aid governance. In reviewing a range of ICT-enabled initiatives, Peixoto and Fox (2016) found that many of such actions that claim themselves as social accountability are limited to collection and reporting of administrative data, as opposed to challenging unequal power relations at the level of service delivery. The generation of a varied and vast amount of data or feedback through ICTs run the risk of entering a "black hole" (McGee, Edwards, Anderson, Hudson, \& Feruglio, 2018, p. 11), exposing the weaknesses inherent in such tools in promoting community control over decision-making. Although ICTs in the forms of crowdsourcing techniques and mapping of community needs are increasingly deployed under the rubric of feedback-driven humanitarian action, they tend to fall short of empowering communities in their right to know about the nature and delivery of concrete humanitarian aid (Mulder et al., 2016). An emerging scholarly consensus is that the collection of data or feedback is neither matched by willingness of authorities to empower local communities nor in their capacity to respond to community feedback, which, in turn, tends to fuel mistrust and cynicism among local communities (Herringshaw, 2017; Madon, 2014; Peixoto \& Fox, 2016).

Despite this emerging evidence, how ordinary citizens or civil society actors pursue social accountability activism within the contentious climate of humanitarian disasters, and its potential and limitations in shaping the governance of post-disaster response and recovery, remains scantly understood. The article seeks to address this gap, using the $2015 \mathrm{Nepal}$ earthquake as an empirical context, which sparked various forms of civil society-induced, ICT-enabled social accountability initiatives. In so doing, the article uses Jonathan Fox's definition of social accountability, involving two synergistic metaphors, "voice" and "teeth" (Fox, 2015). The voice here constitutes everyday grievances and demands of service recipients, expressed through collective action by service recipients themselves, or through local civil society or NGOs. Teeth represent the governmental capacity to respond to citizens' voice. As Fox (2015) argues, "voice needs teeth to have a bite-but teeth may not bite without voice" (p. 357). Using this conceptualisation and drawing on an ethnographic case study of MCHD, the study seeks to interrogate both the potential of voice-based, social accountability in a disaster context, together with the bureaucratic and governance capacity ('teeth') in responding to citizen voice. Before introducing the case, a brief overview of the Nepali context follows.

\subsection{The 2015 Nepal Earthquake and its Context}

The 2015 Nepal earthquakes, as previously noted, not only wrought major human suffering but also brought to the public discourse the demands for accountable, resilient and participatory governance of disasters (Government of Nepal, 2015; Lam \& Kuipers, 2019). The immediate response to the earthquake was concerned with rescue and relief involving a range of national and international aid actors, and local volunteers. The emergency phase was followed by recovery and reconstruction programmes, which included provisions for cash assistance and housing reconstruction, among others (Government of Nepal, 2016). Given the differential impacts of the earthquake, the expectations and needs of the affected communities varied across the 14 highly affected districts with diverse socio-economic contexts.

The aftermath of the Nepal earthquake also saw intense public concerns over misallocation, exclusion and corruption in the delivery of humanitarian aid (Regmi, 2016). The early responders to the crisis had to confront intense public demands for transparent and inclusive aid delivery, while also complying with the government's bureaucratic standards of performance (Dhungana \& Cornish, 2019). The contention over the governance of the Nepal earthquake response, however, was hardly independent of the pre-disaster political and governance context of Nepal. As previous research has shown, the governance aspirations and practice of the Nepal earthquake were impacted by, and, in turn, impacted the pre-existing political environment of state-societal mistrust and scepticisms (Yuldashev, 2018). The earthquake struck Nepal at the time when the country was going through a significant political transition, having experienced a ten-year Maoist conflict and recently ushered into a republic set-up following the overthrow of the Hindu Monarchy. The Constituent Assembly, which was expected to transfer the country from a centralised unitary mode of governance to the federal system of governance, having failed to draft the constitution once, continued to struggle in promulgating the new constitution. The implementation of the 'good governance' agenda that had gained renewed attention after the end of the Maoist insurgency had suffered a setback, owing to 
lack of representation and participation of historically disadvantaged citizens in the local decision-making bodies (Sharma, 2012). At the local level, democratic vacuum persisted, with the country having failed to hold local elections in two decades. In the absence of elected representatives, the emergency response to the earthquake at the local level was coordinated by government bureaucrats, raising serious challenges over the representation of local demands, as further discussed in the findings section.

However, this is not to suggest that the emergency response to the earthquake occurred under a complete policy and governance vacuum. The Nepal earthquake response saw the government activating or launching various forms of governance and legislative reforms, and, according to some scholarship, even served as an impetus to promulgate the new constitution in September 2015, less than six months after experiencing the major humanitarian crisis (Yuldashev, 2018). The emergency response was coordinated by the Home Ministry and couched in various pre-existing policy and regulatory measures such as the Natural Calamity (Relief) Act of 1982, the National Reconstruction and Rehabilitation Policy, the National Strategy for Disaster Risk Management, 2009 (Daly, Ninglekhu, Hollenbach, Barenstein, \& Nguyen, 2017; Government of Nepal, 2016), together with other governance frameworks such as the Development Cooperation Policy of 2014 and the Good Governance (Management and Operations) Act, 2008, with the aim to bring uniformity and regularity in aid response (Dhungana \& Cornish, 2019). Besides, the Post Disaster Needs Assessment, which was conducted in the immediate aftermath of the earthquake made explicit the plan to 'build back better' Nepal, by setting up feedback- and grievancehandling mechanisms to promote local participation in earthquake recovery and reconstruction (Government of Nepal, 2015). Despite these commitments, the Nepal earthquake saw localised and collaborative efforts to attend to the humanitarian needs confronting a major setback amidst the government's attempt to take control over the recovery (Wolbers, Ferguson, Groenewegen, Mulder, \& Boersma, 2016). There is now a growing body of evidence that shows how, despite the original policy commitment, the government marginalised local participation in the decision-making, as the planning and decision-making became increasingly centralised and standardised under the command of the National Reconstruction Authority (Daly et al., 2017; Dhungana, in press ; Lam \& Kuipers, 2019).

Despite this broader context and challenges, civil society actors' attempt to promote participation and accountability in the earthquake response constitutes a noteworthy feature of the $2015 \mathrm{Nepal}$ earthquake. The conditions under which such initiatives unfolded, their role, potential and challenges, however, have been a subject of little scholarly attention. The rest of the article seeks to address this gap, drawing on an ethnographic case study of MCHD, as introduced below.

\section{Methodology}

\subsection{The Case: Mobile Citizen Helpdesk}

According to Simons (2009), a case study is "an in-depth exploration from multiple perspectives of the complexity and uniqueness of a particular project, policy, institution, programme or system in a 'real life' context" (p. 21). The current study was designed as an ethnographic case study of MCHD, an accountability campaign spearheaded by two Nepal-based NGOs, Accountability Lab (AL) and Local Interventions Group (LIG). Both AL and LIG are youth-based civil society organisations, with a history of organising information-based, technologicallyoriented transparency and accountability activism in Nepal's development sector.

For Simons (2009), a case study design is based on the unique characteristics of the specific policy or programme under investigation. As such, two distinct aspects of the MCHD informed the selection and analysis of the study. First, the MCHD was launched as an independent, civil society initiative in the immediate aftermath of the earthquake, with an explicit mission to promote, what the organisers termed "people-powered accountability." This feature offered a suitable lens through which the aims, aspirations and struggles of the MCHD actors could be examined. Second, the campaign was initially launched as a small initiative, mobilising local monitors, while also leveraging ICTs (SMS-based reporting, crowdsourcing of local grievances and reporting of feedback). Later, the organisers expanded the outreach of the campaign, having secured funding from an internationally mandated feedback project called Common Feedback Project (CFP). The CFP and MCHD forged a partnership to leverage pre-existing local networks and experiences of AL and LIG in the 14 highly affected districts. This partnership served as a critical window to examine the areas of consistencies and contradictions inherent in the global and local aspirations for accountability in the disaster context.

\subsection{Fieldwork, Data Sources and Analysis}

The case study followed a focused ethnographic approach of data collection involving short-term yet intensive fieldwork comprising a range of data sources (Knoblauch, 2005). Amongst various activities performed under the MCHD, the use of focused ethnography here involves an intensive study of the two main activities: the administration of micro-perception surveys and community meetings.

The author conducted the fieldwork for this study from January to May 2016. It involved sixteen in-depth interviews, comprising staff, activists and affiliates directly involved with the MCHD, and three government officials working in the field of right to information, anti-corruption and public-sector accountability, with close knowledge of the MCHD. Interviews with the 
MCHD actors and affiliates mostly focused on capturing their motivation of and experiences in initiating and implementing the campaign, their struggles in engaging with local authorities and aid actors, and their sense of accomplishments and limitations in serving in the capacity of local monitors. The interviews with three government officials were mainly concerned with understanding the general context of accountability-related reforms and challenges facing Nepal, before and after the earthquake.

The study also draws on participant observation of the everyday activities of the campaign organisers in the Kathmandu office, including attendance at various formal and informal meetings and workshops. The Kathmandu Office of the MCHD was a major hub, from where most of the field activities were organised and coordinated, offering more in-depth insights into the ways of practising accountability. Participant observations in the Kathmandu office also involved interactions with the staff and collaborators of the campaign in a more casual setting.

Besides, the fieldwork also involved two group interviews with community monitors and district coordinators in two earthquake-affected districts. The group discussions sought to uncover local-level possibilities and challenges in implementing the campaign, coupled with understanding the local monitors' sense of successes, struggles and frustrations. A review of key campaignrelated documents such as progress reports to the donors, website materials, terms of reference and guidelines for local staff and various iterations of community feedback reports complemented the analysis.

The LSE's Ethics Committee granted ethical approval for the study. Interviews were conducted upon securing informed consent from the interviewees, and they lasted for up to 90 minutes. The names of the two organisations involved in the campaign are disclosed with permission from the main coordinators of these organisations, but the identities of individual interviewees are withheld, as per the original ethical approval.

For Simons (2009), the organising and analysis of ethnographic data are to "begin at the beginning" (p. 119). Accordingly, the majority of field notes from participant observations were written while in the field. The intuitive memos, or initial interpretations, while carefully distinguished from the main observations or data, were developed focusing on what seemed interesting, what struck as significant, odd or puzzling and how different pieces of information related to each other (Simons, 2009). To ensure necessary rigour and validity to data analysis, the analysis then carefully followed the ethnographic analytical techniques proposed by Gobo (2008) and LeCompte and Schensul (2013). The analysis involved detailed and repeated reading, and coding of three sets of data aided by the NVivo 11 software, based on the original aim of understanding the potential and limitations of social accountability in a postdisaster context.

\section{Findings}

The findings are divided into two main parts. The first describes the role and practice of social accountability in terms of its potential for building local voice and securing the state's response (teeth), while the second part draws attention to two main impediments facing MCHD. Findings are substantiated by individual and group interview quotes, identified as INT for interviews, GINT 1 and GINT 2 for two group interviews, and OB for the observation notes.

\subsection{Putting Social Accountability into Practice}

\subsubsection{Bridging the Supply-Demand Gap through Local Monitoring}

The MCHD was initially set up with a vision of what the organisers called "people-powered accountability." It was established as a "virtual space" of aid monitoring, leveraging ICTs in the forms of SMS-based reporting, crowdsourcing of grievances, and mobilisation of a network of community monitors, called Community Frontline Associates (CFAs). The role of CFAs was to build an environment of community vigilance against potential exclusion, misuse and corruption of humanitarian resources. As the main strategy, the MCHD campaign engaged investigative journalists because of their "influence and power" at the community level. Although the topic demands future investigation, several of the CFAs were also involved in the informal networks of local volunteers, who worked closely with the local governmental and non-governmental relief and recovery agencies, including the humanitarian clusters working in areas of housing, water and sanitation, food security, etc. The local embeddedness of the CFAs and their ability to "extract and publicise information" was considered pivotal to bring transparency in local aid distribution. The interviewees concurred that, since the majority of the CFAs came from the earthquake-affected communities, who in many instances were themselves the survivors of the earthquake, they were uniquely suited to capturing and publicising grievances of local communities.

\subsubsection{Information as Aid Entitlement}

For the MCHD campaigners, the unprecedented influx of humanitarian aid in the aftermath of the Nepal earthquake was not accompanied by credible information: what the aid items entail, whom the aid is primarily targeted to, from whom it was provided, and how it could be availed. For interviewees, such ambiguity in aid distribution constituted a major accountability gap. One recurring example raised was that concerning access to "victim cards" issued by the government. Although ownership of the victim card was a prerequisite for securing cash and other forms of assistance from the government and aid 
agencies, many affected households were described as either unaware about or uncertain to the future benefits that its ownership guaranteed. As one of the campaign organisers stressed, making local communities aware of the value of such documentation was intrinsic for the local communities to claim future entitlements:

It is difficult to make people realise that information is more useful than rice. Information gives you power, and that gives you empowerment to go to the government and say give me this, and I have the right to this. Another thing we do a lot is how people get the victim card. People don't realise how important it is to get the victim card. Rice will finish. But empowerment and information are something that will stay with you. (INT, 24/02/2016)

The approach of promoting information as aid entitlement evolved, as the overall disaster response itself shifted from immediate rescue and relief effort to future recovery. One of the main organisers of the MCHD described this shift as performing the role between "eyes" and "ears". While "eyes" here was suggestive of being vigilant about the sources of and discrepancies in aid delivery, "ears" meant being sensitive to the demands, grievances and criticisms prevalent in local communities.

\subsubsection{Bringing Voice to the Attention of the "Right Authority"}

For the MCHD actors, the massive response to the Nepal earthquake also brought with it the risk of aid resources being misappropriated and misused. The role of the MCHD campaign was articulated as promoting local vigilance against possible aid diversion and misappropriation, while also providing communities with a channel to raise their concerns "to the right authority":

I think whatever problem we see in Nepal, the main cause is the lack of accountability. There is corruption, mismanagement, misuse of public funds and these are all linked to accountability. I don't think people question the right authority. People are always raising questions, but they are not raising questions to the right authority. So we have started to work on this. (INT, 07/03/2016)

For the above interviewee, the public concerns regarding corruption and misappropriation of public resources were historically prevalent. Yet, the influx of aid resources following the earthquake injected a renewed sense of urgency to address such concerns. One mechanism through which the MCHD sought to address this concern was through local meetings, designed to provide local communities with the opportunity to voice their concerns. Local officials, in turn, could provide justifications of their actions or inactions. In articulating the relevance of such meetings, one interviewee noted that, in many instances, communities' grievances were limited to "tea-stall conversation", which typically escaped the attention of local authorities. For this interviewee, community meetings served to amplify the "tea-stall conversation" into a public conversation. Proceedings of such meetings were captured and circulated through local media and community radio stations affiliated with the campaign. Not only were such meetings described as essential in amplifying local voice for improved humanitarian services, but they were also considered instrumental in tackling growing cynicism and complacency facing affected populations:

The civil space that we created in the form of community meetings are like, the more you interact with the government, the more you know about the services you are entitled to. If that is not done, citizens will say, it is going on, and it will continue like that, nobody will bother to demand more. (INT, 21/03/2016)

Several interviewees acknowledged that organising local spaces did not guarantee immediate redressal of local concerns. Yet, for the community monitors, such meetings had merit on their own, providing local communities with the opportunity to exercise their intrinsic right to demand information and voice concerns regarding the ongoing delays facing disaster recovery.

\subsubsection{Promoting Local Engagement amidst Growing Mistrust}

As described in the introductory section, the postearthquake Nepal proved to be a contested environment, bringing to the centre of the public discourse transparency, corruption and misappropriation in aid response. Faced with slow and uneven aid response, coupled with historical mistrust in local authorities, local communities often accused local officials of neglect, underperformance and misuse of relief funds.

The MCHD actors sought to cast their role in a separate light. Instead of resorting to blaming, alleging and scapegoating individual public officials, the MCHD actors articulated their role within disaster context as promoters of an environment of dialogue and understanding. During one of the group discussions, a community monitor claimed how the exchange of "real information" at the local level helped ease local environment characterised by "rumours" regarding corruption and discrimination in aid allocation. By organising "civic spaces," the MCHD sought to both overcome the local environment of rumours and allegations, while also upholding the affected communities' right to know about aid distribution.

\subsection{Politics of Translation of Community Voice into a Response}

The findings thus far cast a positive spotlight in the way the MCHD conceived and pursued social accountability 
in post-earthquake Nepal. However, the study also highlights the conditions that affect such practice and its effectiveness, particularly in terms of translating community 'voice' into 'teeth' from local powerholders.

\subsubsection{De-Politicisation of Voice and Rights through Humanitarian Technologies}

The MCHD campaign, as previously mentioned, was launched with a political mission of "people-powered accountability," geared at altering unequal power relations at the local level of aid delivery. As one of the coconvenors mentioned, the MCHD campaign was focused on "hyper-localisation of information" through a range of strategies such as "follow the money," crowdsourcing of local complaints, and organisation of community meetings. These strategies were expected to improve community vigilance over aid distribution, amplify local grievances and empower local communities to demand concrete action from the local authorities. However, the process of promoting "hyper-localisation of information" took a technocratic turn as the campaign became increasingly embedded with the monitoring logic of CFP, as further elaborated below.

The CFP was an internationally funded humanitarian feedback project that the MCHD received funding from and became part of after operating for a few weeks as a much smaller-scale campaign. The CFP, in turn, had its origin in the Communicating with Communities Working Group, a globally mandated platform, involving key humanitarian actors. One of the aims of CFP was to promote two-way communication between disasteraffected communities and humanitarian actors, using contextually relevant tools of monitoring and community engagement (Office for the Coordination of Humanitarian Affairs \& Nepal UN Resident Coordinator's Office, 2015, p. 2). Like MCHD, the CFP was also informed by the principles of community engagement, information collection and monitoring. But, in practice, the CFP's treatment of and approach towards information and monitoring deviated from, and subsequently interfered with, how the MCHD actors saw the potential of data in promoting "people-powered accountability."

As part of the partnership between MCHD and CFP, the local monitors, or CFAS, were responsible for conducting micro-perception surveys on a bi-monthly basis. Feedback was to be collected from the earthquakeaffected communities about their perceptions in how humanitarian activities in areas of housing, cash provisions, food services, among others, were being executed at the local level. The processing of feedback, in turn, was done by the donor itself. Dissemination of the feedback was done through a common web portal, as well as in the form of summary reports, which were routinely circulated in the meetings of donors and government officials such as the Community Engagement Working Group meetings.

While the MCHD actors did not resent collection and dissemination of community feedback in itself, they expressed ambiguity as to how the large volume of reports and "success stories" so generated were acted upon to inform future aid programming. Take, for instance, the following comment:

The donor tells us that we need these many reports, these many success stories, but I don't think the reports are being used. I don't even know why they want daily reports. Even for them, the daily reports are the same. How do they analyse up to 70 reports a day? And most of them are in the Nepali language. I used to go home and try to work on those reports even at home. But later I stopped doing it. I used to ask my colleagues how they used the reports, for what purpose? And nobody knew. (INT, 25/02/2016)

The routine collection of community feedback also led to the MCHD actors questioning their sense of agency and power within the aid partnership. When asked to describe how they see the role of the MCHD actors within the aid partnership, one of the campaign's coconveners offered the following reflection:

If I have to say in frank words, we are contractors. Like, if you are building a house, you have to get bricks, you have to bring various construction materials, you don't go around buying them on your own. You get hold of a contractor, and the contractor will bring someone to work as a builder, a carpenter and so on. We are the contractor [for the donor]. (INT, 03/02/2016)

The term "contractors" here evokes a technical role of managing the local surveyors and routine collection and reporting of data. As other interviewees also concurred, under the aid partnership the MCHD campaign became limited to an administrative project involving a mechanical exchange of data and reports, and occasional negotiation of operational changes, budgeting decisions with the funder. Such administrative activities came at the expense of amplifying the local voice and enabling local communities with the information to demand aid entitlements.

A striking tension ensued when, as part of the partnership, the CFP required the community monitors to collect the feedback using smartphone technologies. A two-day workshop was organised in Kathmandu to orient the CFAs to the techniques and practicalities of collecting real-time community feedback through smartphones. The stated goal of the mobile-based surveys was to bring efficiency and accuracy in the collection and dissemination of community feedback. Amidst much enthusiasm, quick piloting of the mobile-based surveys was done in Kathmandu, and soon afterwards, the mobile-based feedback surveys were rolled out across 14 earthquake-affected districts.

Although the interviewees concurred that the introduction of mobile-based surveys brought enhanced effi- 
ciency in collecting and reporting feedback, which in the past was conducted in paper formats, they mentioned having struggled to cope with the undue pressure to come up with timely and error-free feedback. They raised questions over specific aspects of technology-induced feedback collection that the CFAs saw having little relevance to building voice at the local level. As one example, the mobile-based surveys required mandatory recording of the exact field location of surveys, to ensure quick and accurate reporting and processing of community feedback. For CFAs, however, this was an attempt to bring increased surveillance over and discipline in survey administration. Furthermore, it also represented a dwindling level of trust between the central and the local staff. A participant in one of the focus groups raised his concern over the significance of the mobile-based feedback, beyond its use as "a very good experiment":

As I said, if we want to see this [mobile-based feedback] in a positive light, this is a very good experiment. But if you look at it more negatively, this is the case of not trusting. Whether one is in the field or not, whether they are working from home or actually in the field. That I think is their focus. (GINT 2, 31/05/2016)

The CFAs expressed having struggled to comprehend the importance accorded to their physical whereabouts when the focus should be on listening to and publicising local grievances. They raised concerns for being increasingly put under technological surveillance, as the campaign steadily shifted from monitoring the delivery of humanitarian aid to a project involved in the monitoring of CFAs themselves. The Kathmandu-based staff, in turn, were compelled to devote most of their time orienting themselves about the technology-driven techniques of data collection and reporting. A "Project Manager" with "monitoring and evaluation" skills was hired to monitor the unfolding of the mobile-based feedback survey closely. The reshuffling of staff was also felt inevitable. The CFAs, who were initially valued for their "influence and power" and their ability to "extract and publicise information" at the local level, were considered increasingly incompatible with the growing technical demands of the time-bound, donor-funded feedback project.

As per the CFAs, the changing local context also demanded an adaptive approach to the monitoring of humanitarian performance. As most of the CFAs came from journalistic and activist backgrounds, they saw the mobile-based feedback collection along standardised questions to have stifled the possibilities of 'listening' to, and pursuing and publicising stories that reflect the changing demands and concerns of the local communities. The community meetings, which the CFAs concurred of having been instrumental in promoting local scrutiny and engagement, were suspended without much consultation with the CFAs. The MCHD convenors attribut- ed this decision mostly to the lack of funding. This decision left the CFAs further detached from local communities, who they thought were becoming increasingly sceptical of the value of recurring feedback surveys. A CFA, in one of the group discussions, reflected by saying that communities probably consider them as government "spies," recurrently visiting earthquake-affected families to take stock of "household wealth" to determine the nature of aid for each household. Questions were raised over the continuing insistence from the donor to capture local grievances along with pre-defined questions, to the neglect of other ways of listening to community grievances and rumours that were part of the original practice of "people-powered accountability."

\subsubsection{Engaging with the "Right Authority": Who is Accountable to Whom?}

As previously noted, a central goal of the MCHD campaign was to build an environment of local vigilance. Part of the effort was to ensure local grievances are responded to by "the right authority." However, the actual practice of bringing local voice to the attention of "the right authority" proved daunting, as the role and responsibility of local and central level agencies became ambiguous. As one interviewee put it:

The main challenge after the crisis has been that the line agency for VDCs is the Ministry of Local Development and Federal Affairs. How about the line agency that is responsible for earthquake recovery? There is so much confusion, whether it is Home [ministry], whether it is CDO [Chief District Officer], whether it is LDO [Local Development Officer], or NRA [National Reconstruction Authority]. Under whose jurisdiction is disaster recovery? So, OK, we collect grievances, who is supposed to address them? Only if these grievances are addressed on time, then people will start having trust [in the authority]. (INT, 18/04/2016)

The fact that the disaster response demanded sharing of the public service delivery responsibility with a range of domestic and international humanitarian agencies further compounded the situation. A participant of a focus group discussion expressed that the uncertainty in the aid delivery role between NGO and state actors, and by extension their authority and obligation to respond, also added to their dilemma as accountability actors:

People even say that if the concerned authority does not listen to our demands, we will be forced to protest. But the confusion is who that concerned authority is? In the post-earthquake situation, there are two major concerned authorities. First, there is the government, and then there are other relief agencies. (GINT 1, 24/05/2016) 
Despite the MCHD actors' awareness of growing community grievances over sluggish recovery efforts, a lack of clear lines of responsibility among government and nongovernmental agencies made it difficult for the MCHD actors to build on community voice to demand action.

The transitioning political context of Nepal further compounded the situation. As discussed in the introductory section, the earthquake struck Nepal when the local bodies lacked elected representatives, posing a significant crisis of representation at the local level. In the absence of elected representatives, the MCHD monitors had to engage with local bureaucrats, whom the interviewees described having neither enough incentive nor the authority to redress community concerns. They were primarily concerned with coordination of local activities of various governmental and non-governmental agencies.

Getting a response from local officials proved further elusive as the disaster recovery efforts became further centralised under the command of the National Reconstruction Authority, a newly constituted national body to oversee policy and programmatic aspects related to disaster recovery. Although the CFAs view that localised efforts such as community meetings were vital to alleviate local level mistrust and misunderstanding, they were sceptical about their ability to generate a concrete response to the satisfaction of local communities:

So when we do the community level meetings, we mostly have VDC secretary as the lowest level government official. But they cannot answer the questions. They say this is all we know; this is all our authority. They say 'whatever [aid] we have received, we have distributed them as per the rules and regulations of the government.' They also don't give any assurance. (GINT 1, 24/05/2016)

The interviewees described that the post-earthquake environment was characterised by ambiguity in the roles and responsibilities of various implementing agencies. Such uncertainty, together with lack of elected officials, and limited incentive and authority facing local government bureaucrats, posed a challenge for the MCHD actors' efforts to amplify local voice and demand action from the authorities.

\section{Discussion and Conclusion}

Although the 2015 Nepal earthquakes sparked major public concerns over the governance of the disaster, previous research has shown that the Nepali government response fell short in offering concrete mechanisms for the affected populations to participate in and scrutinise the response to the earthquake (Lam $\&$ Kuipers, 2019). Furthermore, in more unequal and resource-constrained societies such as Nepal, historical mistrust in the public sector, the possibility of backlash from powerholders, and low level of public sector responsiveness often serve as impediments for disad- vantaged communities to participate in local decisionmaking and exert pressures on powerholders (Gurung, Derrett, Gauld, \& Hill, 2017). The role of locally embedded intermediary actors can, therefore, be instrumental in cultivating local voice and vigilance in the delivery of public goods (Herringshaw, 2017).

The present article underscores the potential of local activists in serving in the role of such intermediary actors, or what Twigg calls "accountably by proxy" (Twigg, 1999, p. 55), scrutinising aid response and demanding the state's response on behalf of those who are disadvantaged in the face of a major disaster. Driven by the vision of "people-powered accountability," and mobilising a network of local monitors, the MCHD campaign not only enabled the crisis-affected communities with the right to know about aid entitlements but also sought to bring local grievances to the attention of powerholders. The 'proxy accountability role' assumed by MCHD actors is consistent with the notion of what Nicole Curato, through her ethnographic inquiry into the 2013 Typhoon Haiyan in the Philippines, has termed "surrogate publics," spanning community activists and advocates who seek to empower disaster-affected communities with voices of "care" and "justice"(Curato, 2019, p. 54), and, in so doing, promote democratic and inclusive governance of disaster.

In the post-earthquake Nepali context, the proxy accountability role of MCHD actors can be further illustrated by their approach to tackling the problem of mutual voicelessness at the local level. Mutual voicelessness here is suggestive of an environment in which the disaster-affected communities faced a situation of growing uncertainty, primarily owing to an informational and representational vacuum at the local level. Local authorities, in turn, were overburdened and had limited opportunity to engage with communities confronting major crisis and uncertainty. As previous research has shown, the uncertain nature of the Nepal earthquake response, together with public perceptions regarding exclusionary aid distribution, exposed the risk of local-level conflict (De Juan, Pierskalla, \& Schwarz, 2020). Such risk can hardly be overlooked in a society with a recent history of violent conflict and fragile political situation. Besides, the lack of participatory mechanisms constrained disasteraffected communities' ability to avail timely material aid such as cash assistance, temporary shelters, etc., fuelling an environment of local anxiety, rumours and allegations. Through face-to-face meetings, or what one interviewee termed "civil space," the MCHD actors sought to afford local communities with the platform to express their everyday concerns and grievances. Local powerholders, in turn, had the opportunity to render accounts of their performance and dispel allegations. The article shows the potential of localised social accountability activism in promoting the rights and voice of disasteraffected communities, while also helping overcome the post-disaster environment of mistrust, unfounded allegations and power inequalities at the local level. 
Notwithstanding the above potential of civil societybased social accountability in a disaster context, the article draws attention to two key conditions that tend to undermine the outcome of such accountability, particularly when examined through the analytical lens of voice and teeth (Fox, 2015).

First, the study shows the tendency of globally promoted rationalities and technologies of humanitarian accountability undermining locally embedded accountability activism. Through project partnership with globally mandated CFP, a small-scale MCHD campaign was able to command a national presence, mobilising an extensive network of local monitors across 14 disaster-affected districts. The partnership, however, came with a cost. As the MCHD became increasingly embedded in the CFP, it became myopic in scope (Ebrahim, 2005), with the local monitors consumed with the task of routine collection and reporting of community feedback as per the terms of the partnership arrangement. The funding partnership turned the MCHD campaign into a "thermostat approach to accountability" (Ramalingam, 2013, p. 105), focused on monitoring and self-correcting the performance of humanitarian actors, while the possibilities of local activists in promoting local voice and vigilance became sidelined. Not only does such approach to accountability represent a long-standing problem of the international aid community in misrepresenting varied forms of community voice as mere feedback (Madianou et al., 2016), it also underscores how privileging technologyinduced surveys risks triggering undue tension among pro-accountability activists, putting the collective vision of "people-powered accountability" in serious jeopardy.

Second, despite the MCHD's aim to promote "peoplepowered accountability" on behalf of disaster-affected communities, the potential of the localised accountability campaign proved restrictive owing to the systemic gap in Nepal's public sector, together with lack of formal participatory structures. In particular, the lack of elected officials at the local level, coupled with growing centralisation of decision-making under the command of the National Reconstruction Authority, emerged as a challenge to engage with "the right authority." This lesson complements the growing body of literature that underscores the limitations of civil society-driven social accountability activism in the absence of supportive government structures and capacity (Peixoto \& Fox, 2016 , p. 35). A key lesson from this study is that proaccountability activists may need to be better prepared at engaging with different types of anti-accountability structures across varying levels of administrative scales (Fox, 2016). In view of the fluid and elusive nature of authority structures that take root in the post-disaster context, as the article has shown, localised post-disaster accountability activism may have to be complemented by more assertive, advocacy-oriented measures that are targeted to policy actors, legislatures and political representatives, to broaden the scope of democratic governance of humanitarian disasters.
In sum, the article draws attention to the potential of social accountability in making the notions of rights and voice concrete in the interest of disaster-affected communities, and in addressing the post-disaster environment of mistrust, unfounded allegations and power inequalities. The article also concludes that the civil society actors' efforts to improve democratic governance of disasters may prove limiting, unless there are corresponding changes in the national and international structures of accountability in a post-disaster situation.

\section{Acknowledgments}

The author would like to extend special thanks to members of the Mobile Citizen Helpdesk campaign, Accountability Lab, Nepal, and Local Interventions Group, Nepal, for agreeing to share their aspirations and experiences. The article forms part of the author's PhD research at LSE and the in-progress versions of the article were presented at various academic meetings at the LSE and beyond. The author would like to thank the participants of those meetings for providing invaluable feedback. Special thanks to Dr. Flora Cornish, LSE, for her supervision and inputs. Also, thanks to the two anonymous peer reviewers and the editorial team for their comments.

\section{Conflict of Interests}

The author declares no conflict of interests.

\section{References}

Barnett, M. N. (2013). Humanitarian governance. Annual Review of Political Science, 16(1), 379-398.

Biradavolu, M. R., Blankenship, K. M., George, A., \& Dhungana, N. (2015). Unintended consequences of community-based monitoring systems: Lessons from an HIV prevention intervention for sex workers in South India. World Development, 67, 1-10.

Björkman, M., \& Svensson, J. (2009). Power to the people: Evidence from a randomized field experiment on community-based monitoring in Uganda. The Quarterly Journal of Economics, 124(2), 735-769.

Bukenya, B. (2016). From social accountability to a new social contract? The role of NGOs in protecting and empowering PLHIV in Uganda. The Journal of Development Studies, 52(8), 1162-1176.

Caseley, J. (2006). Multiple accountability relationships and improved service delivery performance in Hyderabad City, Southern India. International Review of Administrative Sciences, 72(4), 531-546.

CHS Alliance, Group URD, \& The Sphere Project. (2014). Core humanitarian standard on quality and accountability. CHS Alliance, Group URD and The Sphere Project. Retrieved from https://corehumanitarian standard.org/files/files/Core\%20Humanitarian\%20 Standard\%20-\%20English.pdf

Curato, N. (2018). From authoritarian enclave to deliber- 
ative space: Governance logics in post-disaster reconstruction. Disasters, 42(4), 635-654.

Curato, N. (2019). Democracy in a time of misery: From spectacular tragedies to deliberative action. Oxford: Oxford University Press.

Daly, P., Ninglekhu, S., Hollenbach, P., Barenstein, J. D., \& Nguyen, D. (2017). Situating local stakeholders within national disaster governance structures: Rebuilding urban neighbourhoods following the 2015 Nepal earthquake. Environment and Urbanisation, 29(2), 403-424.

De Juan, A., Pierskalla, J., \& Schwarz, E. (2020). Natural disasters, aid distribution, and social conflict: Microlevel evidence from the 2015 earthquake in Nepal. World Development, 126. https://doi.org/10.1016/ j.worlddev.2019.104715

Dhungana, N., \& Cornish, F. (2019). Beyond performance and protocols: Early responders' experiences of multiple accountability demands in response to the 2015 Nepal earthquake. Disasters. Advanced Online Publication. https://doi.org/10.1111/disa.12425

Dhungana, N. (in press). The politics of participatory disaster governance in Nepal's post-earthquake reconstruction. In M. Hutt, M. Liechty, \& S. Lotter (Eds.), Epicentre to aftermath: Rebuilding and remembering in the wake of Nepal's earthquakes. Cambridge: Cambridge University Press.

Ebrahim, A. (2005). Accountability myopia: Losing sight of organisational learning. Nonprofit and Voluntary Sector Quarterly, 34(1), 56-87.

Fox, J. (2007). The uncertain relationship between transparency and accountability. Development in Practice, $17(4 / 5), 663-671$.

Fox, J. (2015). Social accountability: What does the evidence really say? World Development, 72, 346-361.

Fox, J. (2016). Taking scale into account in transparency and accountability initiatives. Brighton: Institute of Development Studies.

Gaventa, J., \& McGee, R. (2013). The impact of transparency and accountability initiatives. Development Policy Review, 31, s3-s28.

Gobo, G. (2008). Doing ethnography (A. Belton, Trans.). Los Angeles, CA: SAGE.

Goetz, A., \& Jenkins, R. (2005). Reinventing accountability: Making democracy work for human development. London: Palgrave Macmillan.

Government of Nepal. (2015). Nepal earthquake 2015: Post disaster needs assessment (Vol. A: Key findings). Kathmandu: National Planning Commission.

Government of Nepal. (2016). Nepal earthquake 2015: Post disaster recovery framework 2016-2020. Kathmandu: National Reconstruction Authority.

Gurung, G., Derrett, S., Gauld, R., \& Hill, P. C. (2017). Why service users do not complain or have 'voice': A mixed-methods study from Nepal's rural primary health care system. BMC Health Services Research, 17(1), 1-10.

Hayward, B. (2014). Reimaging and rebuilding local democracy. In B. Bennett, J. Dann, E. Johnson, \& R. Reynolds (Eds.), Once in a lifetime: City-building after disaster in Christchurch (pp. 179-185). Christchurch: Freerange Press.

Herringshaw, V. (2017). Addressing failure in ICT-enabled 'citizen voice-government responsiveness' interventions: Unpacking core assumptions and essential components. Brighton: Institute of Development Studies.

Hossain, N. (2010). Rude accountability: Informal pressures on frontline bureaucrats in Bangladesh. Development \& Change, 41(5), 907-928.

Jalali, R. (2002). Civil society and the state: Turkey after the earthquake. Disasters, 26(2), 120-139.

Joshi, A. (2014). Reading the local context: A causal chain approach to social accountability. IDS Bulletin, 45(5), 23-35.

Knoblauch, H. (2005). Focused ethnography. Forum Qualitative Sozialforschung/Forum: Qualitative Social Research, 6(3). Retrieved from http://nbnresolving.de/urn:nbn:de:0114-fqs0503440

Lam, L. M., \& Kuipers, R. (2019). Resilience and disaster governance: Some insights from the 2015 Nepal earthquake. International Journal of Disaster Risk Reduction, 33, 321-331.

LeCompte, M. D., \& Schensul, J. J. (2013). Analysis and interpretation of ethnographic data: A mixedmethods approach (2nd ed.). Lanham, MD: Rowman Altamira.

Madianou, M., Ong, J. C., Longboan, L., \& Cornelio, J. S. (2016). The appearance of accountability: Communication technologies and power asymmetries in humanitarian aid and disaster recovery. Journal of Communication, 66(6), 960-981.

Madon, S. (2014). Information tools for improving accountability in primary health care: Learning from the case of Karnataka. In B.-S. Gigler \& S. Bailur (Eds.), Closing the feedback loop: Can technology bridge the accountability gap? (pp. 189-209). Washington, DC: The World Bank.

Makuwira, J. (2006). Aid partnership in the Bougainville conflict: The case of a local women's NGO and its donors. Development in Practice, 16(3/4), 322-333.

McGee, R., Edwards, D., Anderson, C., Hudson, H., \& Feruglio, F. (2018). Appropriating technology for accountability: Messages from making all voices count. Brighton: Institute of Development Studies.

McMurren, J., Bista, S., Young, A., \& Verhulst, S. (2017). Nepal: Open data to improve disaster relief. Retrieved from http://odimpact.org/files/casenepal.pdf

Meier, P. (2015). Digital humanitarians: How big data Is changing the face of humanitarian response. New York, NY: Routledge.

Mulder, F., Ferguson, J., Groenewegen, P., Boersma, K., \& Wolbers, J. (2016). Questioning big data: Crowdsourcing crisis data towards an inclusive humanitarian response. Big Data \& Society, 3(2), 1-13. 
O'Connor, D., Brisson-Boivin, K., \& Ilcan, S. (2014). Governing failure: Development, aid and audit in Haiti. Conflict, Security \& Development, 14(3), 309-330.

Office for the Coordination of Humanitarian Affairs, \& Nepal UN Resident Coordinator's Office. (2015). Interagency common feedback project: Nepal earthquake 2015. Nepal: UN Country Team in Nepal.

Papp, S. A., Gogoi, A., \& Campbell, C. (2013). Improving maternal health through social accountability: A case study from Orissa, India. Global Public Health, 8(4), 449-464.

Peixoto, T., \& Fox, J. (2016). When does ICT-enabled citizen voice lead to government responsiveness? IDS Bulletin, 47(1), 23-40.

Peruzzotti, E., \& Smulovitz, C. (2002). Held to account: Experiences of social accountability in Latin America. Journal of Human Development, 3(2), 209-230.

Raju, E., \& da Costa, K. (2018). Governance in the Sendai: A way ahead? Disaster Prevention and Management: An International Journal, 27(3), 278-291.

Ramalingam, B. (2013). Aid on the edge of chaos: Rethinking international cooperation in a complex world. Oxford: Oxford University Press.

Regmi, K. D. (2016). The political economy of 2015 Nepal earthquake: Some critical reflections. Asian Geographer, 33(3), 77-96.

Sandvik, K. B., Jumbert, M. G., Karlsrud, J., \& Kaufmann, M. (2014). Humanitarian technology: A critical research agenda. International Review of the Red Cross, 96(893), 219-242.

Schuller, M., \& Morales, P. (2012). Introduction. In M. Schuller \& P. Morales (Eds.), Tectonic shifts: Haiti since the earthquake (pp. 1-10). Sterling, VA: Kumarian Press.

Sharma, K. (2012). Politics and governance in Nepal. Asia
Pacific Journal of Public Administration, 34(1), 57-69. Shukla, A., Teedon, P., \& Cornish, F. (2016). Empty rituals? A qualitative study of users' experience of monitoring \& evaluation systems in HIV interventions in western India. Social Science \& Medicine, 168, 7-15.

Simons, H. (2009). Case study research in practice. London: SAGE.

The Sphere Project. (2011). The Sphere Project: Humanitarian charter and minimum standards in disaster response. Rugby: Practical Action Publishing. Retrieved from https://www.ifrc.org/PageFiles/ 95530/The-Sphere-Project-Handbook-20111.pdf

Tsai, L. L. (2007). Solidary groups, informal accountability, and local public goods provision in rural China. The American Political Science Review, 101(2), 355-372.

Twigg, J. (1999). The age of accountability?: Future community involvement in disaster reduction. Australian Journal of Emergency Management, 14(4), 51-58.

Webb, M. (2012). Activating citizens, remaking brokerage: Transparency activism, ethical scenes, and the urban poor in Delhi. PoLAR: Political and Legal Anthropology Review, 35(2), 206-222.

Wolbers, J., Ferguson, J., Groenewegen, P., Mulder, F., \& Boersma, K. (2016). Two faces of disaster response: Transcending the dichotomy of control and collaboration during the Nepal earthquake relief operation. International Journal of Mass Emergencies and Disasters, 34(3), 419-438.

Yuldashev, F. (2018). Natural disasters and governance systems: The sociotechnical foundations of postdisaster governance reforms in Nepal (Unpublished Doctoral dissertation). University of Pittsburgh, Pittsburgh, PA, USA. Retrieved from http://d-scholarship. pitt.edu/35262/1/yuldashev_2018.pdf

\section{About the Author}

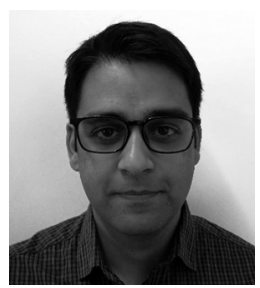

Nimesh Dhungana is a Post-Doctoral Fellow based at the Departments of Methodology and International Development, London School of Economics and Political Science. He is an Interdisciplinary Researcher whose interests span the politics of governance, the interplay of development and disaster, social accountability in the global South, and research designs in the context of complex emergencies. $\mathrm{He}$ also has several years of research experience working in areas of health governance and structural interventions in health. His research focuses on South-Asia, especially Nepal. 